\title{
Factors Which Influence the Growth of Creative Industries: Cross-section Analysis in China
}

Jianpeng Zhang, Jitka Kloudova

\section{Abstract}

With the more and more important roles of creative economy, its research has become one of the major fields in economic development. The creative economy has the potential to generate income and jobs while promoting social inclusion, cultural diversity and human development. As a developing country, China is also in need of developing the creative economy to adjust the economic structure and realize the sustainable development. In this paper, we examined the factors which influence the growth of creative industries in China through the cross-section analysis of 23 regional data in 2007. Four main factors were examined in this multi-regression model, that is, GDP per capita, the number of higher education institutions, the number of students enrolled in higher education institution and the number of patents.

The statistical analysis found that the model's fit is quite good and 69\% of dependent variable (the ratio of value-added of creative industries to the GDP) is explained by the model. Specifically, there are three sub-conclusions. Firstly, there is not a positive relationship between GDP per capita and dependent variable; on the contrary, there is a weak negative relationship in this model. We infer that it is because of the stage of economic development. China heavily depends on the development of the second industry in the process of industrializing. Secondly, there is no linear relationship, in this model, between the number of higher education institutions and the dependent variable. We infer that it is mainly due to the differences between the higher education institutions, such as scales and qualities, etc. Thirdly, there is enough evidence to conclude that the number of students enrolled in higher education institution and the dependent variable are linearly related; the number of patents and the ratio of creative industries are linearly related, as well. They represent the important roles of talents and technology in the development of creative industries.

Keywords: creative economy, creative industries, GDP per capita, multi-regression

JEL Classification: C31, O11 


\section{Introduction}

The development of creative economy has become the engine of economic growth in many regions, especially in developed countries. According to statistical data from UNCTAD, trade in creative goods and services increased at an unprecedented average annual rate of $8.7 \%$ over the period $2000-2005$. This positive trend occurred in all regions and groups of countries and is expected to continue into the next decade, assuming that the global demand for creative goods and services continues to rise (UNCTAD, 2008). The growth rate of creative industries was 6\% per annum between 1997 and 2005 in the UK, which was the double of GDP per capita, $3 \%$ over the same period. The value-added of creative industries is on the secondary place after finance in the UK (DCMS, 2007). What is more, many countries such as Australia, South Korea, Singapore, and the UK have taken the creative industries as a national economic policy.

However, a heated debate has spurred about the definitions and theories of creative industries since the beginning (Howkins, 2007; Hartley, 2005; Florida, 2004; Work foundation, 2007; UNCTAD, 2008, etc.). Although there are many disputes about the definitions of creative economy, economists and scholars are more and more holding the consistent views that the creative industries lay at the center of creative economy.

Generally speaking, there are two categories how to define and analyze the scale of creative industries in developed countries. Firstly, the definition came from the Department for Culture, Media and Sport (DCMS) of the UK in 1997 based on 13 related industries, such as advertising, architecture, art and antiques, crafts, design, fashion, film, music, performing arts, publishing, software and computer games, television and radio. According to this definition, the Creative Industries accounted for $7.3 \%$ of Gross Value Added (GVA) in the UK in 2005, excluding crafts and design. And World Intellectual Property Organization (WIPO) researched the contribution of copyright-based industries to the economy in many countries, such as the US, Canada, Singapore, Bulgaria (WIPO, 2004). The research showed that the "total" of copyright industries is higher accounting for an estimated 12\% of the U.S. GDP and the "total" copyright industries employed $8.41 \%$ of U.S. workers in 2002.

Secondly, it represented the definition of Florida, who defined the creative economy from the view of occupations - creative class. This is a relatively broad definition comparing with the first category. The professionals include Creative Professionals and Super-Creative Core. In this definition, not only the occupations are included in the first category, but also healthcare, business and finance, the legal sector, and education knowledge-based workers. According to his research, 30\% of the U.S. workforce belongs to creative class and nearly $70 \%$ of the discretionary income (buying power) is controlled by creative class in the U.S. (Florida, 2002).

As a developing country, China's creative economy falls behind the developed country, but has a leading position among developing countries. The definitions of creative economy are rich in variety. There are many scholars and local governments identifying culture industries with creative economy, which is called "culture and creative industries". Even in the relatively developed regions, the definitions are quite different as well. Take Beijing and Shanghai as examples. In Beijing, culture and creative industries include nine items: culture and arts; advertisement conference and exhibition; press and publication; arts and antique markets; film and video, television and radio; design services; computer services; tourism, recreation and entertainment; other support services. Shanghai creative industries include research and development design, 
architecture design; culture and art; consulting; fashion consuming, etc. (SCIC, 2009). Both cases showed how big the difference in definitions of creative economy is.

Despite the research running relatively behind, China has made a rapid progress in the last decade. China became the biggest creative goods exporter in 2005 with the $18.3 \%$ market share in the global market. The growth rate of creative goods' export value was 17.6\% from 2000-2005. The exports of new media, if all Chinese regions are considered, reached $\$ 5$ billion in 2005, or about $40 \%$ of global demand (UN, 2008). China has become a middle-level player in the global cultural economy due to its huge population. In addition, nearly a quarter of teenagers live in China. These "youth supplements" are often the risk takers and experimenters, who have huge potential demand for creative products and creative services.

Whatever the definitions, they show the importance of creative economy and creative industries in regional development. However, what are the main factors that influence the development of creative industries? Hong Kong University developed the 5Cs model to research the creativity index in Hong Kong (2005). In this model, it is important to measure not only economic outcomes of creativity but also the cycle of creative activity through the interplay of four forms of capital - social, cultural, human, and structural or institutional - as the determinants of the growth of creativity - the creative capital. The accumulated effects of these determinants are the "outcomes of creativity”.

Florida has researched the creative class and creative index for many developed countries, mainly including the U.S., Canada and the EU, using the so-called 3Ts model. The creative class constitutes the core of innovative industries, is the engine of regional development in the creative era. In Florida's 3Ts model, technology, talent and tolerance are the three main factors influencing the creative economy (Florida, 2002). Due to the close relationship between education and talent, the function of higher education institution (including college, university - undergraduate and postgraduate) was analyzed by Florida and Gates, etc. (2006). The Work Foundation (2007) argued that there are eight broad areas, or drivers, which have an impact on the performance of the creative industries, such as demand, greater diversity, a level playing field, education and skills, networks, etc. Some of these can be influenced by government, some by industry. UNCTAD (2008) argues that most significant drivers of growth in the creative economy are technology, demand and tourism.

There should be different factors for the development of creative industries between the developed countries (or regions) and developing countries (or regions) due to the different stage of economic development. Some scholars have used the modified model to research the influencing factors for the countries which are in the different economic stage. Hansen and Asheim (2009), etc., analyzed the relevance of Florida's theory for European regional development and they got the 'fuzzy' results which didn't solely favor Florida or his opponent. Zhang and Kloudova (2008) researched the correlation of creative index and GDP per capita in China using the modified Florida's 3Ts model. They found that there is a good relationship between the creative index and GDP per capita in China. Kloudova (2009) used a simple model of the 3Ts for regions in the Czech Republic. It was found that the economic growth in the Czech Republic has no connection with the growth rate conditions for the creative economy. There was no dependence between GDP per capita and creativity measured by creativity index. 
In this paper, we analyzed the factors which influence the growth of creative industries in China through the cross-section analysis. The second part is methodology. The definition of creative industries and the chosen variables were discussed in this part. The third part consists of the statistical findings and the assessment of model. The data are mainly from the Statistical Yearbook 2008 for 23 regions of China and some other related official institutions. In the fourth part we examined the required conditions and the last part is conclusion.

\section{Methodology}

\subsection{The definition of creative industries}

As already indicated in the introduction, there are no uniform definitions of terms related to the issues of creative industries. It is not defined, which enterprise belongs to the creative industries and what to include in creative products. According to Kloudova (2010), the reasons for these shortcomings can be seen in the different perception of culture and arts in various countries, in different perception of creativity and creative activities, in fact that creativity is not an output but input into the production process and, last but not least, in fact that creativity is not a measurable input.

Creativity is an important source and production factor in the creative industry and its manifestation is creative thinking, inspirations and ideas. If we want to statistically capture the outputs of creative sector, creative industry, we are dealing with a problem, on what basis to determine which company falls within the creative industry and which does not. Where a product creation was associated with a large part of creativity, it would be very difficult to subtract it from the output afterwards. We believe that the starting point for a certain possibility of mapping the state of creative economy, its development and future possibilities can be only sought in the source of creativity, i.e. the man himself. So far, the most convincing work in this regard is the work of R. Florida, which demonstrates the emergence of the creative economy on the increase in the number of creative workers in the U.S. and defines the so-called creative class, which at the beginning of the century accounted for 10\% of the total workforce, while in 1990 this share increased up to $30 \%$ and the income of the workforce in this class in 2000 amounted to $50 \%$ of total wages in the U.S. (Florida, R., 2002 b).

We assume that the statistical data, which seek to capture the emergence of creative industry, should be based primarily on the concept of creative input, thus the quantity and price of work of the creative personnel involved in the output. This view of the growth of wealth in relation to workers in High Tech Firms may be found in the work of Kraftova, I., Kraft, J. (2008). Thereby, it would be possible to detect the size of creative input even in sectors which are not primarily included in the creative industries and exclude such outputs that already show signs of industrial and mass production and thus are not creative products.

\subsection{The definition of creative industries in this model}

For the feasibility of research and the accessibility of the data, we used the broad definition of creative industries based on Florida's definition of creative class. The premise is that the industries where the employment was mainly comprised by creative 
class can be considered as creative industries. Thus, the creative industries include seven related industries in our model, that is:

1) Information Transmission, Computer Services and Software

2) Lease and Business Affairs Services

3) Scientific Research, Polytechnology Services and Geological Prospecting

4) Culture, Sports and Recreation

5) Banking and Insurance

6) Education

7) Health Care, Social Security and Social Welfare

This definition is based on Florida's definition of creative class and combined economic stage of China, which is highly consistent with the Florida's creative class model. There are at least three common characteristics in these industries as follows: First, they are knowledge-based industries that need a big mount of expert knowledge and have relatively complicated jobs. Second, the creative and innovative jobs take the majority in these industries. Therefore, the majority workers in these industries are creative workers, that is, creative class. Third, they are all a sub-group of tertiary industry (or service industry). If the creative industries defined by the DCMS are called the narrow definition, the definition in this paper can be called the broad definition. Table 1 compared the definition in this paper with that of Florida and DCMS. In the previous research, we used this definition to analyze the creative index in China for each region. The results showed that there is significant correlation between the creative index and GDP per capita.

Tab. 1: The comparison of definition of creative industries

\begin{tabular}{|c|c|c|}
\hline The definition in this paper & Florida's definition & DCMS \\
\hline $\begin{array}{l}\text { Information transmission, } \\
\text { Computer services and } \\
\text { Software }\end{array}$ & Techies & Software and computer games \\
\hline $\begin{array}{l}\text { Lease and Business affairs } \\
\text { services }\end{array}$ & Business & Architecture, design \\
\hline $\begin{array}{l}\text { Scientific Research, } \\
\text { Polytechnology services and } \\
\text { Geological prospecting }\end{array}$ & $\begin{array}{l}\text { Scientists, engineers, techies, } \\
\text { innovators, and researchers }\end{array}$ & \\
\hline Culture, Sports and Recreation & $\begin{array}{l}\text { Artists, designers, writers and } \\
\text { musicians }\end{array}$ & $\begin{array}{l}\text { Advertising, art and antiques, } \\
\text { crafts, fashion, film, music, } \\
\text { performing arts, publishing, } \\
\text { television and radio }\end{array}$ \\
\hline Banking and insurance & finance & \\
\hline Education & education & \\
\hline \multirow[t]{2}{*}{$\begin{array}{l}\text { Health care, Social security } \\
\text { and Social welfare }\end{array}$} & healthcare & \\
\hline & the legal sector & \\
\hline
\end{tabular}

Sources: [1] FLORIDA, R. The Rise of the Creative Class. $1^{\text {st }}$ ed. New York: Basic Books, 2004, paperback. pp. 67-82. ISBN-10 0-465-0247-7

[2] WORK FOUNDATION. Staying ahead: the economic performance of the UK's creative industries. London: DCMS. 2007. pp. 30-50 
In order to get comparable data, we also adjusted some part of definition. There will be some disputes about whether the sports, geological prospecting and social welfare belong to creative industries. However, we must have a trade-off between being able to say something based on compromise and being able to say nothing. There are two reasons why we include these industries: First, parts are controversial. Although some experts don't agree that these industries are creative industries, some others agree. Second, the biggest advantage of this definition is that we can use the data from Statistical Yearbooks for most of regions.

\subsection{Hypotheses}

As a new economy model, the creative economy in developed countries is more advanced than in developing countries. With the development of economy, the ratio of agriculture and industry to GDP is decreasing and the ratio of tertiary industry is increasing (Except for the special stage of economy, such as the developing and least developed countries). Therefore, the knowledge-based economy and creative economy should also be consistent with the stage of economy development. This leads to hypothesis 1 (H1):

H1: Regions with higher GDP per capita have a higher ratio of creative industries' value added to GDP (hereinafter referred to as "The ratio of creative industries").

In Florida's 3Ts model, the talent is one of the most important indicators for the development of creative economy. Talent is also a key intermediate variable in attracting high-technology industries and higher regional incomes. Florida, etc. (2006) examined the higher education institution's role in the creative economy through the lens of the "3Ts" of economic development: technology, talent, and tolerance. Firstly, higher education institutions are often at the cutting edge of technological innovation as major recipients of both public and private $R \& D$ funding, and as important hotbeds of invention and spin-off companies. Secondly, higher education institutions affect talent, both directly and indirectly. They directly attract faculties, researchers and students, while also acting as indirect magnets that encourage highly educated, talented and entrepreneurial people and firms to locate nearby, in part to draw on the higher education institutions' many resources. Thirdly, large research on higher education institutions helps open a regional environment to new ideas and diversity. They attract students and faculties from a wide variety of racial and ethnic backgrounds, economic statuses, and national origins. Higher education institution communities are meritocratic and open to difference and eccentricity; they are places where talented people of all stripes interact in stimulating environments that encourage open thinking, self-expression, new ideas, and experimentation. The higher education institution thus comprises a powerful creative hub in regional development. Therefore, hypothesis 2 (H2) and hypothesis 3 (H3) are developed the following way:

H2: Regions with a higher number of higher education institutions have a higher ratio of creative industries.

H3: Regions with a higher number of students enrolled in higher education institution have a higher ratio of creative industries.

The importance of technology in economy development has been examined by many economists. Technology is one of the most important factors to improve people's living standards in the long run (Barro, 2003). Nowadays, digital and internet technology has 
also crucial influence on the whole production chain of creative goods and services from creation, production to distribution and consumption, e.g., from Computer Aided Design to on-line shopping. The convergence of multimedia and telecommunication technologies has led to an integration of the means by which creative content is produced, distributed and consumed and has in turn fostered new forms of artistic and creative expression.

Underlying these developments has been a more general trend in economic policy-making towards a broadening of the concept of "innovation" from the one concerned only with science and technology into a more wide-reaching appreciation of the role of creativity in the economy. Opening up the idea of creativity as a driving force in the knowledge economy pushes the creative industries into the spotlight as a primary source of the skilled workforce that can produce creative ideas and make innovation happen across a wide range of activities from business entrepreneurship to imaginative new social programmes (UNCTAD, 2008).

In addition, Florida (2002) found that both innovation and high-tech industry are strongly associated with locations of the creative class and talent in general. Zhang and Kloudova (2008) analyzed the high relationship between the technology and creative index in China. This leads to hypothesis 4 (H4):

H4: Regions with high patents per capita have a higher ratio of creative industries.

\section{Model}

\section{Dependent variable}

In this model, the dependent variable is the ratio of value-added of creative industries to the GDP, denoted by y. The value of variable is accounted in percents. The value-added of creative industries is a sum of seven sub-creative industries in our definition. The data of $y$ and GDP for regions are from the regional Statistical Yearbook 2008. The data from 23 regions were researched in this paper because of the data availability.

\section{Independent variables}

Based on the previous analyses and hypotheses, four factors are included in our model as the independent variables. They are GDP per capita, the number of higher education institutions, the number of students enrolled in higher education institution per 10 thousand people and the number of patents per 10 thousand people, which are denoted by $\mathrm{x}_{1}, \mathrm{x}_{2}, \mathrm{x}_{3}, \mathrm{x}_{4}$, separately. The coefficients of independent variables are $\beta_{1}, \beta_{2}, \beta_{3}$, $\beta_{4}$. The data of GDP per capita and the numbers of enrolled students are from the regional Statistical Yearbook 2008. The number of higher education institutions comes from China Education and Research Network (2010). The number of patents is from the State Intellectual Property Office of China in 2008.

Thus, the model is represented by the following equation:

$$
y=\beta_{0}+\beta_{1} x_{1}+\beta_{2} x_{2}+\beta_{3} x_{3}+\beta_{4} x_{4}+\varepsilon
$$

$\mathrm{y}=$ the ratio of value-added of creative industries to regional GDP, in percents

$\mathrm{x}_{1}=$ GDP per capita (yuan)

$\mathrm{x}_{2}=$ number of higher education institutions 
$\mathrm{x}_{3}=$ number of students enrolled in higher education institution (per 10 thousand people)

$\mathrm{x}_{4}=$ number of patents per 10 thousand people)

$\varepsilon=$ the error variable

\section{Statistical findings of model}

According to the definitions of creative industries in this paper, we got comparable data of dependent variable and independent variables from the 23 regions. From Table 2 is visible that the top three regions are Beijing, Shanghai and Guangdong according to the ratio of creative industries to regional GDP, which are $43.08 \%, 25.47 \%, 16.54 \%$, separately. Table 3 is the summary output of statistical data analysis by Microsoft Excel. In the following part, the meanings of the output of statistical analysis are interpreted and the validity of the model is examined.

Tab.2: The basic data of dependent variable and independent variables

\begin{tabular}{|c|c|c|c|c|c|c|}
\hline No. & Region & $\begin{array}{l}\text { the Ratio } \\
\text { of CI to } \\
\text { Regional } \\
\text { GDP }\end{array}$ & $\begin{array}{l}\text { GDP per } \\
\text { capita }\end{array}$ & $\begin{array}{l}\text { No. of } \\
\text { higher } \\
\text { education } \\
\text { institution }\end{array}$ & $\begin{array}{c}\text { No. of } \\
\text { enrolled } \\
\text { students per } \\
10 \text { thousand }\end{array}$ & $\begin{array}{l}\text { Patents per } \\
10 \text { thousand } \\
\text { people }\end{array}$ \\
\hline & & $\mathrm{y}$ & $\mathrm{x}_{1}$ & $x_{2}$ & $x_{3}$ & $\mathrm{x}_{4}$ \\
\hline 1 & Beijing & 43.08 & 58204 & 86 & 462.52 & 9.16 \\
\hline 2 & Tianjin & 15.01 & 46122 & 26 & 360.30 & 5.01 \\
\hline 3 & Shanxi & 10.97 & 16945 & 49 & 147.70 & 0.59 \\
\hline 4 & Inner Mongolia & 8.41 & 25393 & 22 & 118.11 & 0.55 \\
\hline 5 & Liaoning & 10.67 & 25729 & 61 & 199.44 & 2.24 \\
\hline 6 & Jilin & 12.98 & 19383 & 49 & 187.12 & 1.05 \\
\hline 7 & Shanghai & 25.47 & 66367 & 58 & 307.35 & 13.18 \\
\hline 8 & Jiangsu & 13.27 & 33928 & 109 & 205.76 & 4.17 \\
\hline 9 & Zhejiang & 15.87 & 37411 & 68 & 173.71 & 8.31 \\
\hline 10 & Anhui & 13.24 & 12045 & 47 & 113.64 & 0.56 \\
\hline 11 & Fujian & 13.77 & 25908 & 93 & 149.42 & 2.17 \\
\hline 12 & Shandong & 9.17 & 27807 & 88 & 158.76 & 2.44 \\
\hline 13 & Henan & 8.67 & 16012 & 90 & 119.32 & 0.75 \\
\hline 14 & Hubei & 15.24 & 16206 & 84 & 204.12 & 1.16 \\
\hline 15 & Guangdong & 16.54 & 33151 & 84 & 124.26 & 5.97 \\
\hline 16 & Guangxi & 12.93 & 12555 & 37 & 89.86 & 0.40 \\
\hline 17 & Hainan & 11.43 & 14555 & 13 & 127.52 & 0.35 \\
\hline 18 & Chongqing & 13.97 & 14660 & 28 & 137.79 & 1.54 \\
\hline 19 & Guizhou & 15.64 & 6951 & 34 & 62.90 & 0.46 \\
\hline 20 & Gansu & 11.82 & 10346 & 28 & 120.76 & 0.39 \\
\hline 21 & Qinghai & 13.12 & 14257 & 8 & 92.40 & 0.40 \\
\hline 22 & Ningxia & 15.31 & 14649 & 10 & 102.27 & 0.49 \\
\hline 23 & Xinjiang & 14.13 & 16950 & 18 & 107.87 & 0.73 \\
\hline
\end{tabular}


Tab. 3: Summary output of model

\section{SUMMARY OUTPUT}

\begin{tabular}{lr}
\hline \multicolumn{2}{c}{ Regression Statistics } \\
\hline Multiple R & 0.8320 \\
R Square & 0.6922 \\
Adjusted R Square & 0.6238 \\
Standard Error & 4.3329 \\
Observations & 23 \\
\hline
\end{tabular}

ANOVA

\begin{tabular}{lrrrrr}
\hline & $d f$ & $S S$ & $M S$ & $F$ & Significance $F$ \\
\hline Regression & 4 & 759.87 & 189.97 & 10.12 & 0.0002 \\
Residual & 18 & 337.93 & 18.77 & & \\
Total & 22 & 1097.80 & & & \\
\hline
\end{tabular}

\begin{tabular}{lrrrr}
\hline & Coefficients & Standard Error & $t$ Stat & P-value \\
\hline Intercept & 10.74 & 2.87 & 3.74 & 0.0015 \\
x1 & -0.0005 & 0.0002 & -2.0646 & 0.0537 \\
x2 & -0.024 & 0.033 & -0.746 & 0.4654 \\
x3 & 0.07 & 0.020 & 3.46 & 0.0028 \\
x4 & 2.27 & 0.85 & 2.67 & 0.0157 \\
\hline
\end{tabular}

\subsection{Interpretation}

The statistical analysis was conducted by Microsoft Excel. The regression model is estimated by

$$
y=10.74-0.0005 x_{1}-0.024 x_{2}+0.07 x_{3}+2.27 x_{4}
$$

We assess the model in three ways: the standard error of estimate, the coefficient of determination, and the F test of the analysis of variance.

\section{Standard error of estimate}

We judge the magnitude of the standard error of estimate relative to the values of the dependent variable, and particularly to the meaning of $y$. In this model, the standard error is 4.33 and the average of y is 14.81 (not shown in printouts). It appears that the standard error of estimate is not particularly small.

\section{Coefficient of determination}

Table 3 shows that the $\mathrm{R}$ square is 0.69 . It means that the $69 \%$ of the variation is explained by the four independent variables, while $31 \%$ remains unexplained. And the adjusted $\mathrm{R}$ square is 0.62 , which is very similar to the $\mathrm{R}$ square. It means that the sample $\mathrm{n}$ $(n=23)$ is considerably larger than the number of independent variables $k(k=4)$. Hence, no matter how we measure the coefficient of determination, the model's fit is quite good. 


\section{Testing the validity of the model}

Because there is more than one independent variable, we use the method of analysis of variance (ANOVA) to determine whether that model is valid. To test the validity of the regression model, we specify the following hypotheses:

$$
\begin{aligned}
& \mathrm{H}_{0}: \beta_{1}=\beta_{2}=\beta_{3}=\beta_{4} \\
& \mathrm{H}_{1}: \text { At least one } \beta_{\mathrm{i}} \text { is not equal to } 0 .
\end{aligned}
$$

If the null hypothesis is true, none of the independent variables $\mathrm{x} 1, \mathrm{x} 2, \mathrm{x} 3, \mathrm{x} 4$ is linearly related to $y$, and therefore the model is invalid. If at least one $\beta_{\mathrm{i}}$ is not equal to 0 , the model does have some validity. In ANOVA table, the value of F shows the validity of the model. A large value of $\mathrm{F}$ indicates that a significant proportion of the variation in $\mathrm{y}$ is explained by the regression equation and that the model is valid. A small value indicates that most of the variation in $\mathrm{y}$ is unexplained. The rejection region allows us to determine whether $\mathrm{F}$ is large enough to justify rejecting the null hypothesis. For this test, the rejection region is

$$
\mathrm{F}>\mathrm{F}_{\alpha, \mathrm{k}, \mathrm{n}-\mathrm{k}-\mathrm{l}}
$$

Here, the rejection region (assuming $\alpha=0.05$ ) is

$$
\mathrm{F}>\mathrm{F}_{\alpha, \mathrm{k}, \mathrm{n}-\mathrm{k}-\mathrm{l}}=\mathrm{F}_{.05,4,18}=2.93
$$

As you can see from the printout, $\mathrm{F}=17.14$. The printout also includes the $\mathrm{p}$-value of the test, which is 0 . Obviously, there is a great deal of evidence to infer that the model is valid.

\section{Interpreting the coefficients}

Like all statistics, the coefficients $\beta_{0}, \beta_{1}, \beta_{2}, \beta_{3}, \beta_{4}$ describe the relationship between each of the independent variable and the dependent in the sample. We need to use inferential methods to draw conclusion about the population. Here, the sample consists of the 23 observations. The population is composed of all regions in China.

\section{Intercept}

The intercept is $\beta_{0}=10.74$. Actually, it is meaningless in this model. So, the explanation is not necessary.

GDP per capita

The relationship between the ratio of creative industries and GDP per capita is described by $\beta_{1}=-0.0005$. The p-value is $5.37 \%$, which means that there is weak evidence to infer that the ratio of creative industries and GDP per capita is linearly related. From this number, we learn that, in this model, for each additional yuan of GDP per capita, the ratio decreases on average by $0.0005 \%$ assuming that the other independent variables in this model are held. Changing the units, we can interpret $\beta_{1}$ to say that for each additional 1000 yuan, the ratio decreases by $0.5 \%$.

From the previous analysis, we know that the developed countries have more advanced creative economy compared with the developing countries. Generally speaking, there should be a higher ratio of creative industries if there is higher GDP per capita. But why does it seem contradict here? We infer that it is because of the stage of economic development. Because it is in the process of industrializing in China, it is 
heavily dependent on the development of the second industry, especially industry, but not creative industries for most of regions. For example, for most of middle and western regions, the industries are not so developed, even just in the initial stage. Therefore, the positive relationship probably exists in post-industrial society and advanced regions.

Number of higher education institutions

The coefficient $\beta_{2}=-0.024$ specifies that the relationship between the ratio of creative industries and higher education institution is negative. But the p-value is $46.54 \%$, which means that there is no evidence of a linear relationship between the number of higher education institutions and the ratio of creative industries. This is because it is too broad for using the number of higher education institutions only, considering that there are big differences among higher education institutions, such as scales, quality, etc.

Number of students enrolled in higher education institution

The relationship between the ratio of creative industries and the number of enrolled students is described by $\beta_{3}=0.07$, which we interpret that for each additional college or university student per 10 thousand people, the ratio of creative industries to GDP increases by $0.07 \%$ when the other variables are constant. The t-test is 3.46 with p-value of $0.28 \%$. There is enough evidence to conclude that the number of students enrolled in higher education institution and the ratio of creative industries are linearly related.

Number of patents

The relationship between the ratio of creative industries and the number of patents is described by $\beta_{4}=2.27$, which we interpret that for each additional patent per 10 thousand people, the ratio of creative industries to GDP increases by $2.27 \%$ when the other variables are constant. The t-test is 2.76 and p-value is $1.57 \%$. There is enough evidence to conclude that the number of patents and the ratio of creative industries are linearly related.

\subsection{Residual analysis}

\section{Non-normality}

Figure 1 shows that the histogram is bell shaped, leading us to believe that the error is normally distributed.

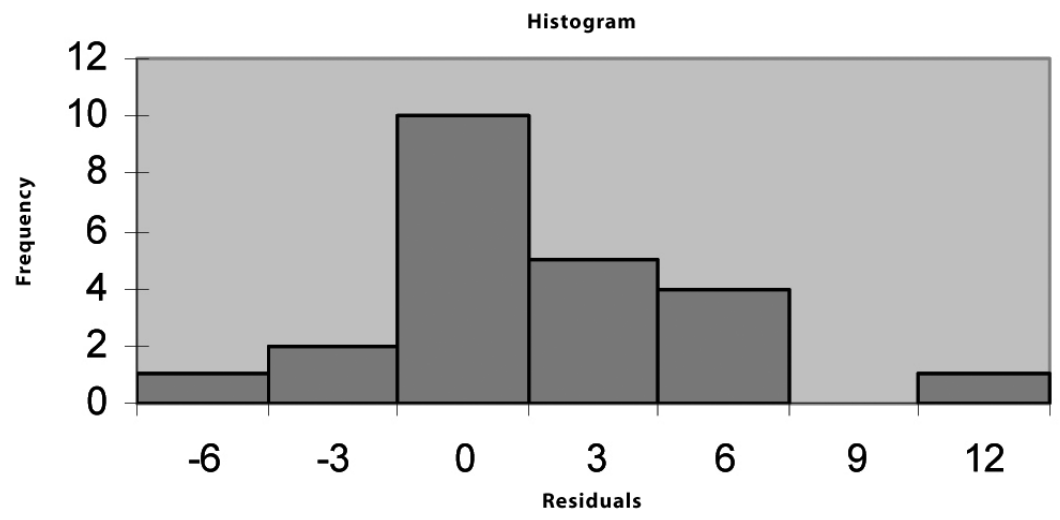

Fig. 1: The histogram of residuals 


\section{Heteroscedasticity}

In Figure 2 to 6 the residuals plots of independent variables are $\mathrm{x}_{1}, \mathrm{x}_{2}, \mathrm{x}_{3}$, and $\mathrm{x}_{4}$. The figures show that there are no signs of heteroscedasticity. Figure 6 is the scatter diagram of residuals versus predicted values. There is also no strong sign of heteroscedasticity, although it is not so perfect, partly due to the sample size, which is not large enough.

Taken together, we can conclude that the required conditions are satisfied.

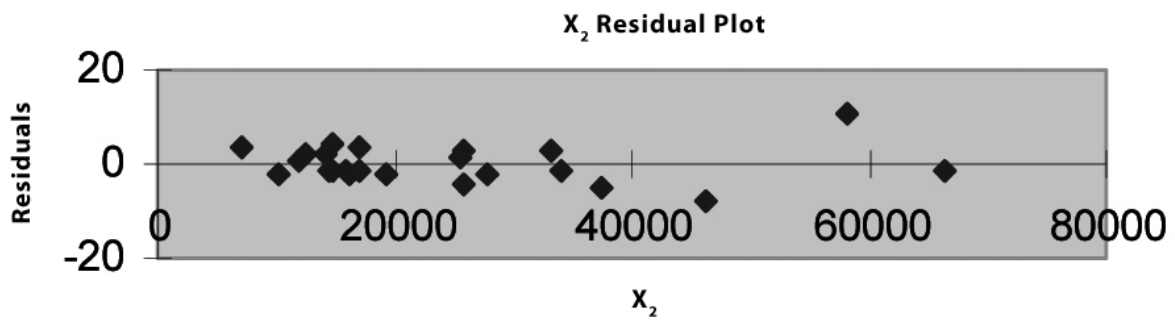

Fig. 2: The Residual Plot of $x_{1}$

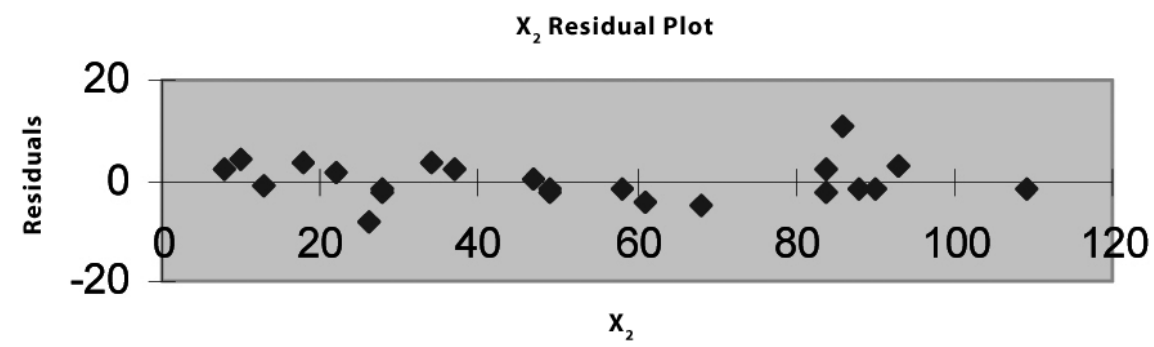

Fig. 3: The Residual Plot of $x_{2}$

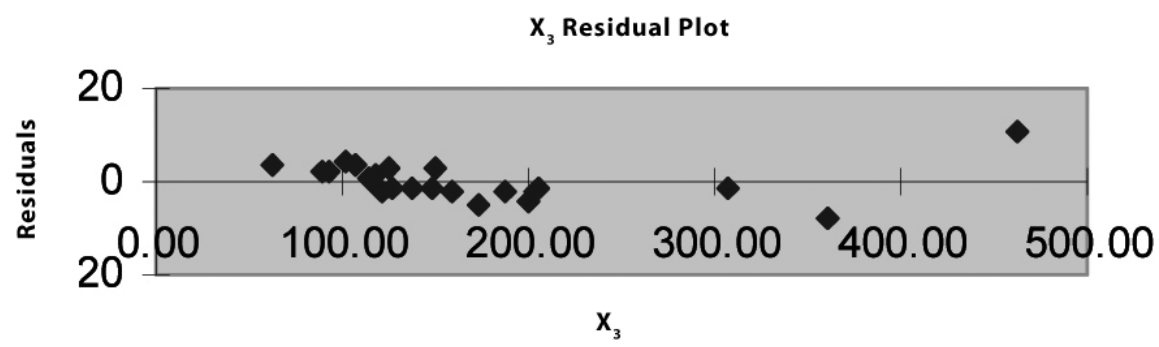

Fig. 4: The Residual Plot of $x_{3}$

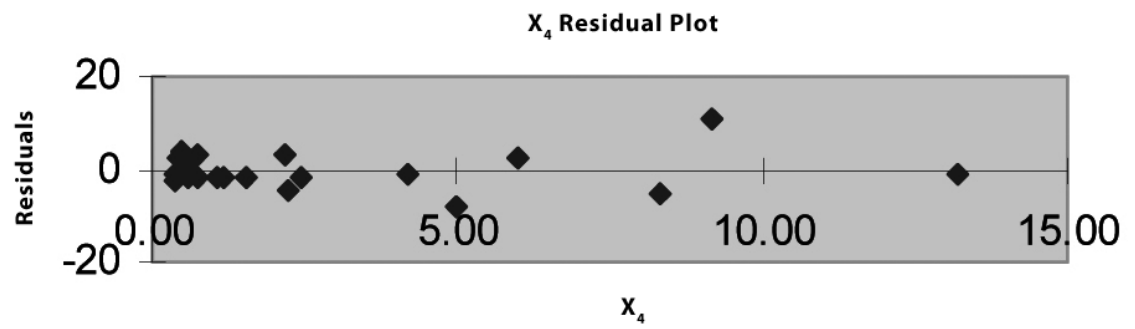

Fig. 5: The Residual Plot of $x_{4}$ 


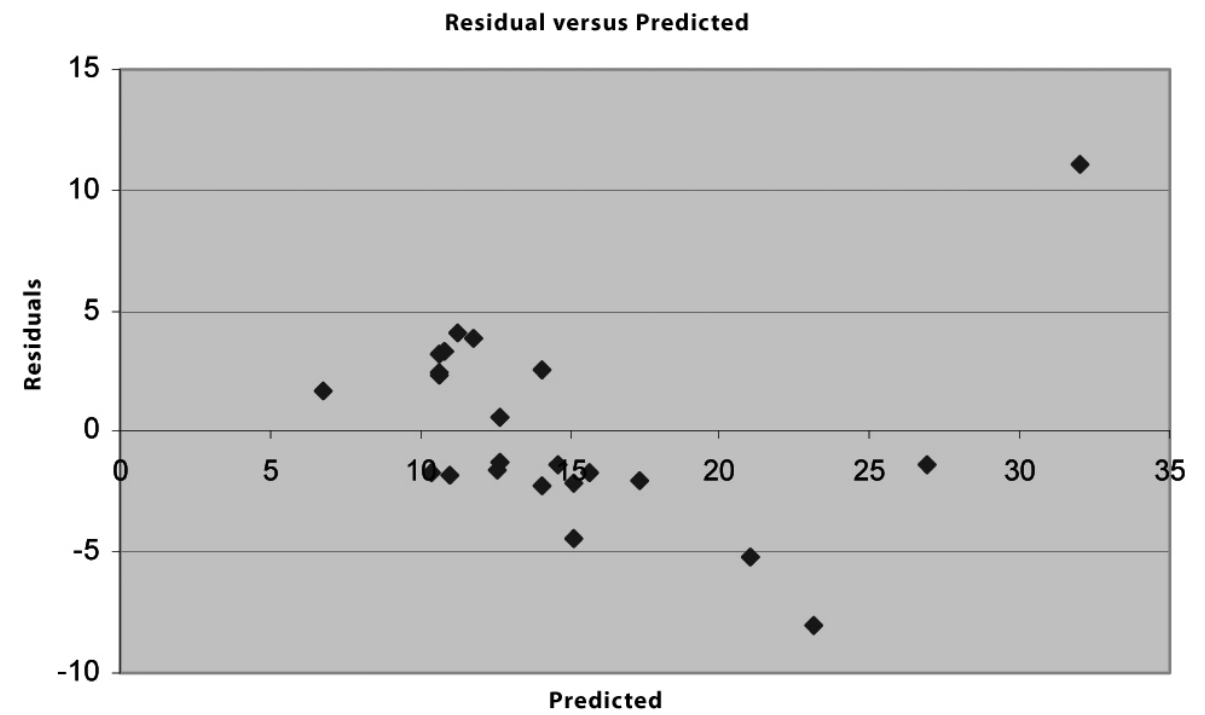

Fig. 6: Residuals versus Predicted

\section{Conclusion}

With the more and more important roles of creative economy, its research has become one of the major fields in economy development. The creative economy is not only the significant sector of economy but also has a big influence on promoting the competitiveness of other related sectors. Generally, we measure the creative economy from three aspects such are the ratio of GDP, employment and the contribution of export in some countries or regions. China's creative economy has made a big progress in recent years, especially in export, but there are still many factors hindering its growth. The growth of creative economy is beneficial to adjusting China's economic structure and realizes the sustainable development as a developing country.

In this paper, we examined the factors which influence the growth of creative industries in China through the cross-section analysis of 23 regional data in 2007. Four main factors were examined in our multi-regression model, that is, GDP per capita, the number of higher education institutions, the number of students enrolled in higher education institution per 10 thousand people and the number of patents per 10 thousand people. The statistical analysis found that the model's fit is quite good and 69\% of dependent variable (the ratio of value-added of creative industries to the GDP) is explained by the model.

There are also some results that do not support our hypotheses for independent variables. Firstly, there is not a positive relationship between GDP per capita and dependent variable; on the contrary, there is a weak negative relationship in this model. We infer that it is because of the stage of economic development. Because it is in the process of industrializing in China, it heavily depends on the development of the second industry, especially industry, but not creative industries for most of regions. Secondly, there is no linear relationship, in this model, between the number of higher education institutions and the dependent variable. We derive that it is mainly due to the fact that there are many differences between the higher education institutions, such as the scale, reputation and quality, etc. Thirdly, there is enough evidence to conclude that the 
number of students enrolled in higher education institution and the dependent variable are linearly related; the number of patents and the ratio of creative industries are linearly related, as well. They represent the important roles of talents and technology in the development of creative industries.

It is worth to mention that not all influential factors are listed and analyzed in this paper. There are also some other factors significant for the growth of creative industries, such as the function of creative cluster, the government policy, the piracy phenomenon, etc. These factors are worth researching in the future.

\section{References}

CHINA EDUCATION AND RESEARCH NETWORK, Available on World Wide Web: <http://www.edu.cn/HomePage/jiao_yu_zi_yuan/college.php>

DCMS, Creative Industries Economic Estimates Statistical Bulletin, October 2007.

FLORIDA, R. The Economic Geography of Talent. Annals of the Association of American Geographers. Dec., 2002, Vol. 92, No. 4, pp. 743-755

FLORIDA, R. The Rise of the Creative Class. And How It's Transforming Work, Leisure, Community and Everyday Life. $1^{\text {st }}$ ed. New York: Basic Books, 2004, paperback, pp. 434, ISBN-10 0-465-0247-7 (pbk)

FLORIDA, R., GATES, G., etc. The University and the Creative Economy. December 2006. Available on World Wide Web: 〈www.creativeclass.com>.

HARTLEY, J. Creative Industries. Oxford: Blackwell Publishing Ltd, 2005, pp. 414, ISBN 1-4051-0147-4

HOWKINS, J. The Creative Economy. How People Make Money from Ideas. $2^{\text {nd }}$ ed. London: Penguin Group, 2007, pp. 269, ISBN 978-0-140-28794-3

Jac,I. (2008). Evaluation of Project in Dimension the Innovation Solution of Disparities. $E+M$ Economics and Management, 2008, Vol.11. Iss.2, pp. 31-40. ISSN 1212-3609

KLOUDOVA, J. Measurement of the Creative Economy. Journal of Economics. Institute of Slovak and World Economics and Institute of Forecasting Slovak Academy of Sciences. Bratislava. 2009, Vol.57, No.3, pp. 247-262

KLOUDOVA, J. Kreativní ekonomika. Trendy, výzvy, př́ležitosti. (Creative Economy). Grada Publishing, a.s., 2010. ISBN: 978-80-247-3608-2

KONG, L., O'CONNOR, J. Creative Economies, Creative Cities: Asian-European Perspectives. In Hansen, H.K., Asheim B., Vang J. The European Creative Class and Regional Development: How Relevant is Florida's Theory for Europe? London: Springer, 2009, pp. 99-120. ISBN: 978-1-4020-9948-9

Kraftova, I., Kraft, J. (2008). High Tech Firms and the Creation of Welfare in the EMEA Countries. E + M Economics and Management, 2008, Vol.11. Iss.4, pp. 6-20. ISSN 1212-3609

NATIONAL BUREAU of STATISTICS. China Statistical Yearbooks [online]. 2008. Available on World Wide Web: 〈http://www.stats.gov.cn/tjsj/ndsj>.

SIPOC (State Intellectual Property Office of China). Domestic Grants for Three Kinds of Patents, 2008. Available on World Wide Web:

< http://www.sipo.gov.cn/sipo2008/ghfzs/zltjjb/jianbao/year2007/b/b3.html>.

STEPHEN, E. S. The Economic Contribution of Copyright-Based Industries in USA: The 2004 Report. Creative Industries Series No.1. World Intellectual Property Organization. 2004.

THE CENTRE for CULTURAL POLICY RESEARCH, the University of Hong Kong, A Study on Creativity Index, 2005 
UNCTAD. Creative Economy Report: The Challenge of Assessing the Creative Economy Towards Informed Policy-making. April 2008, pp. 357, ISBN: 978-0-9816619-0-2

WORK FOUNDATION. Staying ahead: the economic performance of the UK's creative industries. London: DCMS. 2007.

WALL COMMUNICATIONS INC. The Economic Contribution of Copyright-Based Industries in Canada: The 2004 Report. Creative Industries Series No.1. World Intellectual Property Organization. March 31, 2004.

ZHAHG, J., KLOUDOVA, J. Study on Creative Index in China: A Modified Florida's 3Ts Model. Current Issues of Business and Law. 2009, Vol.3, pp.104-117.

\section{Jianpeng Zhang, M.A., Ph.D.}

1980, lecturer, Faculty of Management, Hainan Medical University, China.

e-mail: zlintbu@163.com

\section{Jitka Kloudova,}

Associate professor, Tomas University in Zlin, Faculty of Management and Economics and the Vice-Rector for Research, Pan - European University, Tomášikova 20, 821 02, Bratislava, Slovakia, phone: 02/48208815, E-mail: jitka.kloudova@uninovalsk; kloudova@fame.utb.cz 